\title{
Cooperativismo na agricultura orgânica no Brasil: contribuições de Chayanov
}

\author{
Cooperativism in organic Agriculture in Brazil: contributions of Chayanov
}

\begin{abstract}
Resumo
Este artigo tem como objetivo analisar de que modo o cooperativismo vem contribuindo com a rápida expansão da produção de orgânicos no Brasil. Para tal, busca-se aporte teórico nos escritos de Alexander Chayanov para sustentar o cooperativismo como forma de organização social profícua para o desenvolvimento desse modo de fazer agricultura. A metodologia utilizada se consistiu na análise de dados secundários dos Censos Agropecuários de 2006 e 2017 do IBGE. Os resultados mostram um aumento numericamente expressivo de estabelecimentos agropecuários associados com cooperativas entre os anos de 2006 e 2017. Além disso, enquanto $15,75 \%$ das unidades de produção orgânica certificadas estão associadas com cooperativas, nas unidades não certificadas esse índice atinge apenas 5,33\%. Considerando o potencial do cooperativismo como um modo de organização social, ações do Estado e as políticas púbicas poderiam se beneficiar desta capacidade organizacional para tornar mais efetivas a superação das múltiplas carências dessa categoria.
\end{abstract}

Palavras-chave: Cooperativismo, agricultura orgânica, agricultura familiar, censo agropecuário.

\begin{abstract}
This paper aims to analyze how cooperativism has contributed to the rapid expansion of organic production in Brazil. To this end, we seek theoretical support in the writings of Alexander Chayanov to support cooperativism as a fruitful social organization for the development of this way of doing agriculture. The methodology used consisted of analysis of secondary data from the 2006 and 2017 IBGE Agricultural Census. The results show a numerically significant increase in agricultural establishments associated with cooperative relations between 2006 and 2017. In addition, while $15.75 \%$ of certified organic production units are associated with cooperatives, in non-certified units this index reaches only $5.33 \%$. Considering the potential of cooperativism as a mode of social organization, state actions and public policies could benefit from this organizational capacity to make it more effective to overcome the multiple needs of this category.
\end{abstract}

Keywords: Cooperativism, organic farming, family farming, agricultural census.

${ }^{\mathrm{I}}$ Gean Carlos Tomazzoni, Sergio Schneider ${ }^{\mathrm{II}}$

${ }^{\text {I}}$ Universidade do Rio Grande do Sul - UFRGS, gean.tomazzoni@hotmail.com

${ }^{\text {II }}$ Universidade Federal do Rio Grande do Sul - UFRGS, schneide@ufrgs.br 


\section{Introdução}

A economia clássica alicerçou-se sob a premissa de que o representante Homo economicus, detentor do egoísmo racional, persegue seus objetivos de acordo com o estreito interesse próprio. Os pressupostos subjacentes à literatura econômica clássica sustentam uma lógica de maximização da utilidade pelos consumidores e dos lucros pelas empresas, que negligencia efeitos externos, como a degradação ambiental, levando à noção de que bens comuns serão superexplorados na ausência de mercados ou regulamentação (OLSON, 1965; HARDIN, 1968). Para o mainstream das ciências econômicas, a autossuficiência do mercado é capaz de resolver os dilemas sociais, ou problemas de ação coletiva, nos quais existe um conflito entre os interesses individuais e coletivos (DAWES, 1980).

Entretanto, muitos cientistas sociais expressaram reservas em relação ao realismo do Homo economicus, detentor da racionalidade egoísta penetrante do comportamento humano. As críticas geralmente se concentram em bases lógicas, empíricas e comportamentais. A confluência de estudos tensionando as premissas do Homo economicus fez emergir teorias relacionadas ao comportamento humano, apoiando a ideia de cooperação em várias escalas da sociedade (FEHR; SCHMIDT, 1999; BREKKE; KVERNDOKK; NYBORG, 2003; NYBORG; HOWARTH; BREKKE, 2006; ROEMER, 2010; 2015). Com o propósito de superar os pressupostos do Homo economicus, o conceito de cooperação entrou com alguma força na arena econômica. A publicação seminal de Dawes e Thaler (1988) sustentou uma análise da cooperação como uma das anomalias que não poderiam ser explicadas pela teoria econômica padrão.

Nesse sentido, Ostrom (1990) desafia os quadros teóricos anteriores e os pressupostos da teoria da ação coletiva, especialmente os comuns de Hardin (1968) e Olson (1965), a partir de pesquisas realizadas ao longo de 30 anos sobre as regras dos usos de bens coletivos. Ao investigar tais regras, Ostrom (1990) preconiza a cooperação como elemento essencial para sobrevivência humana, constituindo-a como necessidade vital para encontrar soluções coletivamente para um patrimônio compartilhado, do qual todos dependem. Para Ostrom (2005) a ação coletiva, constituidora de convenções e instituições capazes de desenvolver alternativas de gestão diante de situações tanto triviais como complexas, é retroalimentada constantemente por essas mesmas convenções e instituições, deslocando a segundo plano às soluções oferecidas pela coerção do Estado, ou pelo mercado da firma.

Com efeito, em face dos impasses e trade off gerados tanto pelo capitalismo como pelo socialismo, o cooperativismo vem sendo apontado por estudiosos e homens de negócios como saída razoável ao dilema de Hardin. Pois bem, cientistas sociais de variadas estirpes se dedicaram a este simples problema e concluíram que a melhor resposta ao problema inevitável é o controle e a governança sobre o agir coletivo. Logo, não é difícil imaginar porque o cooperativismo se tornou um dispositivo de maximizar os interesses de grupo sociais e limitar suas ganâncias e riscos associados. Além disso, empiricamente, o cooperativismo é uma das formas de ação coletiva mais acionadas pelos atores socais e agentes econômicos que trabalham no campo do desenvolvimento, quer seja ele com enfoque econômico ou social. Desde os seus primórdios, em 1844, quando um grupo de trabalhadores do bairro de Rochdale, na cidade de Manchester decidiu se unir e fundar um armazém para revenda de produtos a preços inferiores aos praticados no comércio local, a ação coletiva de grupos de indivíduos mostrou suas potencialidades e, sobretudo resultados.

Ao lançar olhares sobre os sistemas agroalimentares, pode-se observar o crescente interesse por práticas de produção de alimentos identificados com a sustentabilidade e a emergência do debate do desenvolvimento sustentável que marcam o século XXI. Com efeito, aflora-se a necessidade de olhares mais atenciosos sobre as formas alternativas de produção agrícola, seus modos de organização social e como a cooperação atua nesse contexto. Se alguns sustentam que a agricultura orgânica é ficção de naturalista inconsequente, outros a vem como uma revolução. Posições menos radicais, no entanto, argumentam que o processo de transformação da agricultura sustentável ocorrerá em paralelo à mudança na agricultura industrial, altamente consumidora de insumos industriais e uso de agroquímicos (BEZERRA; VEIGA, 2000).

Estudiosos apontam que esta mudança já está em curso e vem sendo puxada pelo aumento crescente do consumo de alimentos orgânicos. Segundo relatório da IFOAM (2016), no mundo são cultivados 43,7 milhões de hectares de agricultura orgânica. Ainda, o relatório revela que a demanda 
do consumidor está aumentando, refletindo no crescimento significativo do mercado, que, por consequência, resulta em 2 milhões de agricultores orgânicos no mundo, cujo faturamento anual chega a 60 bilhões de dólares. E o mais interessante é que 80\% destes produtores estão localizados em países em desenvolvimento, como o Brasil (IFOAM, 2016).

Segundo Lourenço, Schneider e Gazzola (2017) a demanda por orgânicos no Brasil cresce de forma rápida e segue uma tendência global, sugerindo que a posição marginal que os orgânicos ocupavam está se modificando de forma acelerada. No cenário nacional, Dalcin et al. (2014) destacam um crescimento de 40\% no mercado de orgânicos entre os anos de 2009 e 2010, alcançando a faixa de 190 milhões de dólares. Essa tendência indica que existe um caminho desafiador a ser conquistado no desenvolvimento da agricultura orgânica no Brasil.

Os dados dos Censos Agropecuários de 2006 e 2017 indicaram que a grande maioria dos estabelecimentos agropecuários orgânicos no Brasil está inserida na categoria agricultura familiar. Além disso, Lourenço, Schneider e Gazzola (2017) verificaram que embora os agricultores "mais estruturados e modernos" sejam representativos no número de estabelecimentos orgânicos, são os agricultores familiares mais pobres que representam a parcela numericamente mais significativa de estabelecimentos que fazem produção orgânica.

Partindo desse contexto, neste artigo pretende-se apresentar uma caracterização do perfil dos estabelecimentos agropecuários que fazem produção orgânica no Brasil e analisar se estão vinculados a cooperativas. O trabalho se baseia nos dados dos Censos Agropecuários realizados em 2006 e 2017 e seu objetivo é analisar de que modo o cooperativismo vem contribuindo com a rápida expansão da produção de orgânicos no Brasil. Nos interrogamos sobre a possível existência de uma maior inclinação dos estabelecimentos agropecuários cooperativistas pela produção orgânica ou; de outro modo, será que unidades de produção cooperativistas são mais permeáveis e inclinadas a produzir mediante o uso de práticas orgânicas?

Com efeito, neste artigo busca-se apresentar uma caracterização dos processos cooperativos presentes nos estabelecimentos agropecuários que fazem produção orgânica no Brasil, com base na sistematização e análise dos dados atualizados obtidos nos Censos Agropecuários 2006 e 2017. Todos os dados secundários referentes aos Censos estão disponíveis no Banco de Dados Agregados do Sistema de Recuperação Automática (SIDRA). Incialmente, foram mapeados dados de matrizes, inseridas no SIDRA, que contemplavam a categoria 'agricultura orgânica'. De posse desses dados, operacionalizou-se a sistematização e a tabulação dos dados usando-se o software Microsoft Excel. Por fim, a partir da análise dos dados, foram realizadas as análises críticas e descritivas sobre a agricultura orgânica no Brasil, mobilizando o repertório teórico acerca da cooperação camponesa de Chayanov (2017), que compõe o essencial da contribuição deste artigo.

Os insights que pretende-se extrair desses dados, porém, não se referem a poder dizer que existem correlações estatisticamente significativas entre agricultura familiar, agricultura orgânica, associação com cooperativas, índices de certificação e etc.. Trata-se, antes, de analisar como as composições desses elementos entre si - certificações, cooperativas, entidades de classe, agricultura familiar, agricultura não-familiar - produzem diferenças, produzem contrastes na agricultura orgânica no brasil. Esses dados podem ser tomados como importantes sinalizadores para análises mais profundas do contexto social no qual tais estabelecimentos que fazem produção orgânica no Brasil estão inseridos e como as formas de cooperação podem potencializar o desenvolvimento da agricultura orgânica no Brasil.

O artigo está estruturado em quatro seções, além dessa introdução. Inicia-se apresentando o trabalho de Alexander V. Chayanov, especialmente a obra "Teoria das Cooperativas Camponesas", recentemente desvelada na literatura e traduzida para o português, constituindo-se como uma lente de análise para a transformação da economia camponesa no âmbito de uma economia de mercado. Na sequência, busca-se apresentar definições e relações da agricultura orgânica e da agricultura familiar no Brasil. Em seguida, apresenta-se alguns dados dos Censos Agropecuários de 2006 e 2017 que permitem uma contextualização preliminar do campo. Finalizando, intenta-se aproximar as contribuições de Chayanov para compreender a organização cooperativa na agricultura orgânica e suas potencialidades. 


\section{Cooperativismo: Contribuições de Alexandre V. Chayanov}

Alexander V. Chayanov é o nome mais importante da chamada Escola da Organização da Produção e da Agronomia Social, que produziu um impressionante volume de informações sobre o meio rural da Rússia. Tal ligação entre um poderoso grupo de intelectuais, com fortíssima raiz local, fez da utopia camponesa de Chayanov não o anúncio obscurantista de uma volta ao passado, mas a base de um projeto cuja atualidade se mantém, não sob a forma apocalíptica por ele assumida, mas por um tema hoje importantíssimo na agenda internacional, o dos laços rural-urbano (ABRAMOVAY, 1998).

Chayanov (2017) discute a transformação da economia camponesa no âmbito de uma economia de mercado, partindo do argumento central de que o sucesso do sistema cooperativo depende do desenvolvimento combinado de diversas formas de organização da agricultura. Ao analisar o contexto russo no início do século XX, o autor problematiza as especificidades da agricultura, em comparação com a indústria, analisando as vantagens consideráveis e as reduções de custos de produção provindas de formas de organização econômica de larga escala, sustentando que na agricultura essas vantagens não são tão aparentes quanto na indústria.

Para Chayanov (2017), quando um agricultor aumenta sua produção, na maior parte dos casos, ele é obrigado a aumentar o número de insumos que utiliza, ao invés de aumentar a escala dos mesmos. Em razão disso, as economias de escala, expressas em termos quantitativos, são menores. Ademais, as características da produção agrícola impõem um limite natural à ampliação de um empreendimento agrícola. Com muita frequência, o trabalho tido como não rentável por uma granja capitalista é lucrativo em uma unidade agrícola familiar voltada para o mercado, e vice-versa. Desse modo, Chayanov (2017) considera que a própria natureza de um estabelecimento agrícola coloca limites à ampliação de sua escala.

A cooperação, é nesse sentido, um meio para conciliar as vantagens da economia de larga escala com as unidades camponesas de pequeno porte que, ao integrarem-se com cooperativas, alcançam uma escala maior do que as propriedades privadas. A unidade rural camponesa integrada à cooperativa pode intensificar o trabalho, gerando crescimento da produção, aumento da riqueza social e distribuição da renda nacional. Por meio da cooperação, se descentraliza a análise da produção em escala. $\mathrm{O}$ importante não é ser muito grande ou muito pequeno, mas ser de tamanho ótimo, balanceando as vantagens e desvantagens da grande ou pequena escala, o que Chayanov (2017), denomina de teoria dos ótimos diferenciais.

Desse modo, com base no plano organizativo da unidade produtiva, considerando seus diferenciais setoriais, seria possível aferir, para cada setor, sua escala ótima específica. Chayanov (2017) sustenta que existe um ótimo para o cultivo de pradarias, outro para a agricultura; e, além disso, um ótimo para o cultivo de grãos, outro para culturas consorciadas, outro para produção de sementes e outros ainda para diferentes formas de processamento - diferente em cada caso e, via de regra, com grande variação. Assim, para o autor, as cooperativas podem representar uma variante altamente aperfeiçoada de economia camponesa, possibilitando ao pequeno produtor separar de seu plano organizativo aqueles itens cuja produção em larga escala apresenta vantagens indubitáveis em relação à de pequena escala. $\mathrm{O}$ camponês consegue organizar a produção desses itens em conjunto com seus vizinhos, de forma a alcançar um modo de produção de grande escala, de forma cooperativa.

Analisando os diferenciais da unidade agrícola e identificando aqueles elementos que são adequados para a cooperação, pode-se elaborar o plano organizativo da unidade agrícola camponesa, com diversas formas de cooperação. As cooperativas não podem ser isoladas das bases econômicas e sociais sobre as quais estão fundadas. Assim, sendo essas bases economicamente diversas, as cooperativas são também de diferentes tipos. As cooperativas organizam os interesses e aspectos das vidas de grupos ou classes que já existiam antes delas surgirem (CHAYANOV, 2017).

Chayanov (2017), analisou o movimento de cooperativas que havia obtido um impulso considerável no campo russo durante os anos que precederam a revolução de 1917. A concepção de cooperação de Chayanov refere-se às cooperativas fortes, seja a montante ou a jusante da unidade camponesa. Acerca do montante, poderia haver cooperativas que produzem e entregam insumos a propriedades camponesas. A jusante, o processamento e a comercialização das diferentes produções 
das unidades camponesas. Estas "cooperativas fornecem aos pequenos empreendimentos todos os benefícios dos grandes" (CHAYANOV, 1988, p.155).

Chayanov (2017) defende a coletivização cooperativa de setores da economia camponesa, como forma de fortalecer o setor e promoção da estabilidade, manutenção e reprodução desses modos de produção camponês. Chayanov desenvolve o conceito de cooperação agrícola total, para apresentar a cooperação como modo de produção camponês, entre pequenos produtores, que facilita o acesso aos meios de produção e às tecnologias, podendo ser estendida para a comercialização dos produtos e acesso ao crédito. Para o autor, as cooperativas podem ser a base sobre a qual se organiza um modelo social e econômico eficaz na alocação individual dos resultados alcançados de forma coletiva (CHAYANOV, 2017).

Além disso, na visão de Chayanov (2017), o cooperativismo das unidades camponesas é a melhor solução frente ao impasse entre a coletivização estatal e o modelo capitalista mercantil, discussão que imperava no modelo russo de agricultura no início do século XX. O desafio da agricultura camponesa, seria harmonizar entre si os princípios organizacionais, por meio do controle do volume de vendas, o desenvolvimento organizacional do sistema e a expansão da base financeira, o que assegura o sucesso da ação cooperativa. Desse modo, o sucesso de uma cooperativa é alcançado pelo crescimento da renda de seus membros e não, necessariamente, pelo "lucro" da própria cooperativa.

Facilitando a extensão do sistema cooperativo à comercialização e ao processamento técnico, as cooperativas agrícolas conseguem a concentração da organização da produção agrícola segundo padrões mais elevados, ajudando os pequenos produtores a adaptarem o plano organizativo de sua unidade e o acesso aos mercados de acordo com a política de comercialização e processamento cooperativo. A coletivização cooperativa, na visão de Chayanov (2017), representa o melhor caminho para introduzir na economia camponesa elementos de uma economia de grande escala, de industrialização e de planejamento estatal. Segundo o autor, a organização das massas camponesas em cooperativas seria uma forma de transformar a agricultura individualista em um sistema econômico cooperativo e coletivo.

No caso brasileiro, Strate (2018) sustenta que as políticas recentes de compras governamentais, que emergiram a partir dos anos 2000, tais como Programa Nacional da Alimentação Escolar (PNAE) e Programa de Aquisição de Alimentos (PAA), trouxeram oportunidades significativas de acesso a mercados para cooperativas da agricultura familiar no Brasil. $\mathrm{O}$ autor também defende que os agricultores familiares estão se inserindo em sistemas cooperativos de produção e geração de renda, bem como na difusão de novos valores culturais, sociais e ambientais, como forma de sobrevivência e novas maneiras de inserção nos mercados. Tal momento, constitui-se como rico para aprofundar a discussão acerca dos processos cooperativos no contexto da agricultura brasileira.

\section{Agricultura Orgânica e Agricultura Familiar: Relações e Delimitações}

O Brasil presenciou nos últimos anos a emergência de uma nova categoria sociopolítica no meio rural, denominada de agricultura familiar, legitimada pelo Estado e pela sociedade, incluindo a produção de um quadro normativo específico para sua definição (Lei no 11.326/2006). A categoria agricultura familiar nasceu das lutas por reconhecimento e direitos empreendidas por uma miríade de atores, especialmente pelos movimentos sindicais do campo. Esses movimentos passaram a reivindicar políticas diferenciadas de desenvolvimento rural, como resposta aos efeitos dos processos de globalização, abertura comercial, crise econômica e esfacelamento da capacidade de intervenção do Estado, legitimados por inúmeros estudos que apontavam para o protagonismo da agricultura familiar para sustentar a produção e a geração de emprego e renda em inúmeros países (NIEDERLE; FIALHO; CONTERATO, 2014).

A agricultura familiar ou "os pequenos agricultores" - como eram denominados antes da criação da categoria sociopolítica - sempre estiveram às margens das ações do Estado brasileiro, não raro incrementando sua fragilidade diante das opções de desenvolvimento perseguidas no país. A nova trajetória dessa categoria, iniciada ainda nos movimentos da criação da Constituição Federal 
em 1988, incitou novos espaços de participação social e reconheceu direitos da agricultura familiar. Políticas públicas, como o Programa Nacional de Fortalecimento da Agricultura (PRONAF) em 1995, a criação do Ministério do Desenvolvimento Agrário (MDA) em 1999, e da Secretaria da Agricultura Familiar (SAF) no ano de 2001, institucionalizaram a dualidade da estrutura agrária e fundiária no país e desencadearam a emergência de outras políticas diferenciadas de desenvolvimento rural (GRISA; SCHNEIDER, 2014).

Se os referenciais da modernização e as teorias marxistas advogavam o fim dos camponeses, no Brasil, assim como em vários outros países, um olhar mais atento do governo e da sociedade para a importância da agricultura familiar no desenvolvimento do país, fizeram florescer condições de reprodução social e econômica da agricultura familiar (GRISA; SCHNEIDER, 2014). Dados do Censo Agropecuário do Instituto Brasileiro de Geografia e Estatística (IBGE, 2017) revelam que 77\% (3,9 milhões) dos estabelecimentos rurais brasileiros são classificados na categoria agricultura familiar e empregam $67 \%$ (10,1 milhões) do total de pessoas ocupadas no setor agropecuário. Entretanto, a agricultura familiar detém apenas 23\% (80,9 milhões de hectares) do total de área rural do país e produz 23\% (R\$107 bilhões) de toda a produção agropecuária brasileira. Quando resgatamos os dados do Censo Agropecuário de 2006, verifica-se que, naquele ano, a agricultura familiar representava $83 \%$ dos estabelecimentos agropecuários (4,3 milhões), detinha 30\% (81,2 milhões de hectares) do total de área rural do país e empregava $84 \%$ (12,1 milhões) das pessoas ocupadas no campo (IBGE, 2006). Ainda, a agricultura familiar é responsável pela produção de $87 \%$ da mandioca, $70 \%$ do feijão, $46 \%$ do milho, $38 \%$ do café, $34 \%$ do arroz e $21 \%$ do trigo do Brasil. Na pecuária, $60 \%$ da produção de leite, além de $59 \%$ do rebanho suíno, $50 \%$ das aves e 30\% dos bovinos do país.

Embora definir o que é a agricultura familiar possa ser uma tarefa difícil, considerando a heterogeneidade da agricultura e das formas de fazer agricultura, conforme a prescrição da Lei no 11.326/2006, é considerado agricultor familiar aquele que não detenha, a qualquer título, área maior do que 4 módulos fiscais; utilize predominantemente mão-de-obra da própria família nas atividades econômicas do seu estabelecimento ou empreendimento; tenha renda familiar predominantemente originada de atividades econômicas vinculadas ao próprio estabelecimento ou empreendimento; dirija seu estabelecimento ou empreendimento com sua família. Também são considerados agricultores familiares: silvicultores, aquicultores, extrativistas, pescadores, indígenas, quilombolas e assentados da reforma agrária (BRASIL, 2006).

Olhando para agricultura orgânica, de acordo com os dados dos Censos Agropecuários de 2006 e 2017, a grande maioria dos estabelecimentos agropecuários orgânicos está inserida na categoria da agricultura familiar. Contudo, conforme Niederle e Almeida (2013), a grande maioria, em torno de 95,17\%, não são certificados, evidenciando ser este um dos grandes desafios da agricultura orgânica no país. Mazzoleni e Nogueira (2006), defendem que o grande potencial brasileiro para a agricultura orgânica são os agricultores familiares. Essa modalidade pode contemplar no mínimo, $70 \%$ dos agricultores brasileiros, que não utilizam químicos e não possuem nenhuma força mecânica para realizarem suas atividades agrícolas.

Veronezzi e Bastos (2012) defendem que a agricultura familiar possui características específicas que vão além das questões econômicas, caracterizando um modo de vida que leva em consideração o trabalho da própria família. Dessa maneira, a agricultura familiar possui as características fundamentais para a possibilidade de organizar a produção de forma orgânica. A agricultura orgânica é vista pelos autores como um modo de fazer agricultura que auxilia no desenvolvimento da agricultura familiar, como alternativa barata para a geração de renda, a diversificação da produção e a utilização de insumos limpos por meio da técnica orgânica, que permitem melhorar as condições de vida das famílias.

Como alternativa ao modelo moderno de produção agrícola, o conceito de agricultura orgânica foi inicialmente desenvolvido por Sir Albert Howad, entre os anos de 1925 e 1930. Esse modo de agricultura emergiu com maior força na década de 1960. Entretanto, por muitos anos a agricultura orgânica foi marginalizada como forma de fazer agricultura. Niederle e Almeida (2013), destacam três elementos que corroboram: a baixa demanda por orgânicos; a carência de tecnologias adaptadas; e, mais fortemente, a ausência de um contexto político-institucional que garanta estabilidade à dinâmica dos mercados de orgânicos no país. Lourenço, Schneider e Gazolla (2017) levantam indícios de que este quadro esteja se alterando, tendo em vista o crescimento da demanda por produtos 
orgânicos, o desenvolvimento de tecnologias apropriadas, o aumento da demanda nos mercados, a mudança de opinião dos consumidores, o potencial da agricultura orgânica e de seu papel para o desenvolvimento sustentável e as nascentes políticas públicas voltadas à agroecologia e produção orgânica.

A agricultura convencional pode ser entendida como aquela ligada ao processo de modernização/conversão tecnológica que culminou na chamada Revolução Verde, principalmente a partir da década de 1970, que contava com importante apoio científico voltado para a produção agrícola intensiva. De outro modo, a agricultura, denominada alternativa, com suas peculiaridades técnicas, ambientais e socioculturais, surgiu como uma forma de contestar os padrões produtivos dominantes ou convencionais, tencionando não apenas as aplicações técnicas de tais padrões e seus resultados produtivos, mas também a concepção de desenvolvimento que os permeia (ALMEIDA, 2009). Os sistemas de produção, designados pelo termo alternativo, apresentam várias denominações, tais como: natural, ecológica, biodinâmica, permacultura, biológica ou orgânica, entre outras.

A agricultura orgânica, na visão de Mazzoleni e Nogueira (2006), pode ser compreendida como um processo de busca da sobrevivência harmônica do ser humano com o seu planeta, uma vez que o desenvolvimento sustentável prega que as necessidades da presente geração sejam atendidas sem sacrificar a possibilidade de as gerações futuras também atenderem suas próprias necessidades. Segundo Altieri (2002, p. 18), "o objetivo é trabalhar com sistemas agrícolas complexos onde as interações ecológicas e sinergismos entre os componentes biológicos criem, eles próprios, a fertilidade do solo, a produtividade e a proteção das culturas". Com efeito, a proposta da agricultura convencional é inconcebível com o atual nível de desgaste dos recursos naturais provocado pela agricultura química.

Reganold e Wachter (2016) analisaram o desempenho da agricultura orgânica à luz de quatro medidas-chave de sustentabilidade: produtividade, impacto ambiental, viabilidade econômica e bem-estar social. Os dados levantados pelos autores evidenciaram que esse modo de produção apresenta rendimentos suficientes aos produtores, ao mesmo tempo em que melhora as condições ambientais e dos trabalhadores rurais. Eles ainda afirmam que unidades de produção orgânica têm o potencial para produzir altos rendimentos em consequência da capacidade mais elevada de retenção de água nos solos cultivados sem agrotóxicos. Em termos financeiros, no entanto, o estudo deixa claro que, apesar de ser rentável, o cultivo orgânico proporciona lucros menores do que as formas tradicionais. A explicação para isso está no barateando dos custos de produção gerados pela utilização de pesticidas. Em compensação o ganho ambiental, social e na própria saúde da população é significativo (REGANOLD; WACHTER, 2016). As evidências apontam para o fato de que os sistemas agrícolas de produção orgânica garantem maior benefício social, o que resulta em um planeta mais sustentável.

O desafio da atualidade é garantir a segurança alimentar, com alimentos saudáveis, e o fornecimento dos insumos necessários para a economia, de forma socialmente justa e sem comprometer o meio ambiente e as gerações futuras. Desse modo, a agricultura orgânica, do ponto de vista governamental, é uma oportunidade de formulação de políticas públicas. O potencial brasileiro para a agricultura orgânica são os agricultores familiares excluídos da agricultura química. Políticas bem planejadas poderiam induzir o desenvolvimento desses agricultores marginalizados. É condição básica, no entanto, que agricultor seja devidamente capacitado, conheça os princípios da agricultura orgânica, os objetivos da visão da propriedade como um organismo, a integração da agricultura e da pecuária para fertilização do solo, a importância da biodiversidade, as práticas ecológicas de conservação e todos os outros conhecimentos para cultivar com eficiência técnica e econômica (MAZZOLENI; NOGUEIRA, 2006).

No cenário brasileiro, o termo agricultura orgânica é encontrado na legislação brasileira, desde a Instrução Normativa № 7, de 17 de maio de 1999 (BRASIL, 1999), consolidando-se na Lei 10.831, de 23 de dezembro 2003 (BRASIL, 2003). Na Lei no $10.831 / 2003$, que dispõe sobre a agricultura orgânica, são considerados como sistema orgânico de produção:

Todo aquele em que se adotam técnicas específicas, mediante a otimização do uso dos recursos naturais e socioeconômicos disponíveis e o respeito à integridade 
cultural das comunidades rurais, tendo por objetivo a sustentabilidade econômica e ecológica, a maximização dos benefícios sociais, a minimização da dependência de energia não renovável, empregando, sempre que possível, métodos culturais, biológicos e mecânicos, em contraposição ao uso de materiais sintéticos, a eliminação do uso de organismos geneticamente modificados e radiações ionizantes, em qualquer fase do processo de produção, processamento, armazenamento, distribuição e comercialização, e a proteção do meio ambiente (BRASIL, 2003, p. 8).

O Censo Agropecuário de 2006 definiu a produção agrícola orgânica como:

Estabelecimentos nos quais foram adotadas práticas de produção agropecuária que não utilizassem insumos artificiais (sendo eles: adubos químicos, agrotóxicos, organismos geneticamente modificados ou outros), bem como outras medidas orientadas para a conservação dos recursos naturais e do meio ambiente (IBGE, 2006, p. 49).

Já o Censo Agropecuário 2017 delimitou o conceito inserindo uma nova variável para levantar as informações acerca da agricultura orgânica, sendo considerados produtores orgânicos apenas as unidades agropecuárias detentoras de certificação da produção. Ocorre com efeito, a inexistência de dados do último Censo referentes a multiplicidade de modos de produção orgânica não-certificados.

Na seção que segue busca-se apresentar alguns dados dos Censos Agropecuários de 2006 e 2017 que permitem uma discussão acerca do contexto da agricultura orgânica no Brasil.

\section{Agricultura Orgânica e a Cooperação}

Para iniciar a discussão levanta-se dados sobre estabelecimentos agropecuários associados a relações com cooperativas, considerando os Censos Agropecuários dos anos de 2006 e 2017. Nos Censos Agropecuários de 2006 e 2017 os dados podem ser segmentados segundo critérios da agricultura familiar e não-familiar, tomando-se por base a definição estabelecida pela Lei 11.326, de 24 de julho de 2006, conhecida como a Lei da Agricultura Familiar (BRASIL, 2006).

Tabela 1 - Número de estabelecimentos agropecuários associados a cooperativas

\begin{tabular}{lcccc|ccc}
\hline \multirow{2}{*}{ Região } & \multirow{2}{*}{ Agricultura } & \multicolumn{3}{c|}{ 2006 } & \multicolumn{3}{c}{2017} \\
\cline { 2 - 8 } & & Total & \multicolumn{2}{c}{ Cooperativa } & \multicolumn{2}{c}{ Total } & \multicolumn{2}{c}{ Cooperativa } \\
\cline { 2 - 8 } \multirow{2}{*}{ Brasil } & \multicolumn{1}{c}{ Total } & 5.175 .636 & 346.369 & $6,69 \%$ & 5.073 .324 & 579.438 & $11,42 \%$ \\
\cline { 2 - 8 } & Não-familiar & 809.369 & 108.533 & $13,41 \%$ & 1.175 .916 & 167.133 & $14,21 \%$ \\
\cline { 2 - 8 } & Familiar & 4.366 .267 & 237.836 & $5,45 \%$ & 3.897 .408 & 859.938 & $22,06 \%$ \\
\hline \multirow{2}{*}{ Norte } & 475.778 & 10.537 & $2,21 \%$ & 580.613 & 20.309 & $3,50 \%$ \\
\hline Nordeste & 2.454 .060 & 32.091 & $1,31 \%$ & 232.2719 & 33.592 & $1,45 \%$ \\
\hline Sudeste & 922.097 & 118.518 & $12,85 \%$ & 969.415 & 165.630 & $17,09 \%$ \\
\hline Sul & 1.006 .203 & 158.428 & $15,75 \%$ & 853.314 & 313.763 & $36,77 \%$ \\
\hline Centro-Oeste & 317.498 & 26.795 & $8,44 \%$ & 347.263 & 46.144 & $13,29 \%$ \\
\hline
\end{tabular}

Fonte: IBGE (2006; 2017).

De acordo com a Tabela 1 é possível observar que em 2006 apenas $6,69 \%$ dos estabelecimentos agropecuários brasileiros possuíam associação com cooperativas, sendo que quando categorizados, verifica-se percentuais superiores para a categoria não-familiar. Assim, é possível observar que na categoria da agricultura não-familiar a associação com cooperativas é proporcionalmente maior do que na agricultura familiar, embora em números absolutos a agricultura familiar apresente valores muito superiores, totalizando 237.836 estabelecimentos agropecuários familiares que possuem associação com cooperativas. Ainda é interessante observar que em 2006 a macrorregião Sul (15,75\%) apresenta o maior valor proporcional $(15,75 \%)$ de 
estabelecimentos associados com cooperativas, seguida das macrorregiões Sudeste (12,85\%) e Centro-Oeste $(8,44 \%)$. As macrorregiões Norte $(2,21 \%)$ e Nordeste $(1,31 \%)$ foram as que apresentaram os menores valores.

Comparativamente, analisando os dados do levantamento de 2017, chama a atenção o aumento expressivo do número de estabelecimentos agropecuários associados com cooperativas. No Brasil, os dados mostram um crescimento de $6,69 \%$ para $11,42 \%$. Chama a atenção o crescimento expressivo verificado na categoria agricultura familiar. Em 2006 foram identificadas 237.836 (5,45\%) unidades agropecuárias associadas com cooperativas. Em 2017 esse indicador passou para 859.938 unidades agropecuárias, representando $22,06 \%$ do total de estabelecimentos da agricultura familiar. Na região Sul, em 2006 eram 158.428 (15,75\%) estabelecimentos associados com cooperativas, em 2017 esse número cresceu para 313.763 (36,77\%). Essa tendência de crescimento se repetiu em todas as macrorregiões do país, embora o crescimento tenha sido menos expressivo.

Tabela 2 - Número de estabelecimentos agropecuários que fazem agricultura orgânica

\begin{tabular}{|c|c|c|c|c|c|c|c|c|c|}
\hline \multirow{3}{*}{ Região } & \multirow{3}{*}{ Agricultura } & \multicolumn{5}{|c|}{2006} & \multicolumn{3}{|c|}{2017} \\
\hline & & \multirow{2}{*}{ Total } & \multicolumn{4}{|c|}{ Agricultura Orgânica } & \multirow{3}{*}{$\begin{array}{c}\text { Total } \\
5.073 .324\end{array}$} & \multirow{2}{*}{\multicolumn{2}{|c|}{$\begin{array}{c}\text { Agricultura } \\
\text { Orgânica Certificada }\end{array}$}} \\
\hline & & & \multicolumn{2}{|c|}{ Total } & \multicolumn{2}{|c|}{ Certificada } & & & \\
\hline \multirow{3}{*}{ Brasil } & Total & 5.175 .636 & 90.498 & $1,75 \%$ & 5.106 & $0,10 \%$ & & 64.690 & $1,28 \%$ \\
\hline & Não-familiar & 809.369 & 15.693 & $1,94 \%$ & 1.490 & $0,18 \%$ & 1.175 .916 & 15.360 & $1,31 \%$ \\
\hline & Familiar & 4.366 .267 & 74.805 & $1,71 \%$ & 3.616 & $0,08 \%$ & 3.897 .408 & $49 \cdot 330$ & $1,27 \%$ \\
\hline Norte & & 475.778 & 6.133 & $1,29 \%$ & 351 & $0,07 \%$ & 580.613 & 7.935 & $1,37 \%$ \\
\hline Nordeste & & 2.454 .060 & 42.236 & $1,72 \%$ & 1.218 & $0,05 \%$ & 232.2719 & 16.710 & $0,72 \%$ \\
\hline Sudeste & & 922.097 & 18.715 & $2,03 \%$ & 1.366 & $0,15 \%$ & 969.415 & 19.666 & $2,03 \%$ \\
\hline Sul & & 1.006 .203 & 19.276 & $1,92 \%$ & 1.924 & $0,19 \%$ & 853.314 & 13.553 & $1,59 \%$ \\
\hline Centro-Oeste & & 317.498 & 4.138 & $1,30 \%$ & 247 & $0,08 \%$ & 347.263 & 6.826 & $1,97 \%$ \\
\hline
\end{tabular}

Os dados da Tabela 2 mostram que no ano de 2006 existiam no Brasil 90.498 estabelecimentos agropecuários que faziam agricultura orgânica, representando apenas 1,75\% do número total de estabelecimentos do país. No levantamento realizado no ano de 2017 , verifica-se que esse indicador passou para 68.716 unidades agropecuárias, representando 1,35\% do total. Ainda, na categoria agricultura familiar, esse indicador passou de 74.805 unidades agropecuárias em 2006 para 49.330 em 2017. Um leitor apressado diria que em 11 anos houve um decrescimento de $28,52 \%$ (25.808 unidades agropecuárias) no número de unidades agropecuárias que fazem produção orgânica no Brasil. Tal resultado seria contraditório com outros estudos que sutestam um aumento na demanda por produtos orgânicos no Brasil (DALCIN et al., 2014; LOURENÇO; SCHNEIDER; GAZZOLA, 2017).

Acontece que houve uma importante alteração no método empregado pelo IBGE para mensurar esse indicador, como mencionado na seção anterior. Em 2006, o IBGE perguntou ao agricultor "você é produtor orgânico?", se a resposta fosse positiva, uma segunda pergunta era introduzida "você possui certificação?". Nesses termos, foi verificado um total de 90.498 estabelecimentos que declararam fazer produção orgânica, sendo que destes 5.106 (5,64\%) eram certificados. No ano de 2017, o IBGE perguntou "você é produtor orgânico certificado?". Nesses termos foi verificado um total de 64.690 estabelecimentos orgânicos certificados. Ou seja, o que é possível concluir é que houve um crescimento exponencial no número de agricultores orgânicos certificados entre os anos de 2006 e 2017. Porém não é possível verificar no Censo de 2017 os resultados sobre os estabelecimentos orgânicos não-certificados existentes no país. É interessante notar que na agricultura familiar, em 2006, apenas 3.616 estabelecimentos eram de produção orgânica certificada. Em 2017 esse indicador passou para 49.330 estabelecimentos agropecuários.

Em 2006, a macrorregião Nordeste apresentou o maior número de unidades agropecuárias que declararam fazer produção orgânica (42.236 unidades), seguida das macrorregiões Sul (19.276 unidades) e Sudeste (18.715 unidades). Embora, ao verificar as unidades que declararam fazer produção orgânica e são certificadas, a posição de liderança era da macrorregião Sul (1.924), seguida das macrorregiões Sudeste (1.366) e Nordeste (1.218). As posições de destaque também foram 
ocupadas pelas macrorregiões Sul (0,19\%) e Sudeste (0,15\%) quando analisada a proporção de unidades que fazem agricultura orgânica certifica sobre o total de unidades agropecuárias da macrorregião.

Em 2017, podendo ser analisadas apenas as informações referentes as unidades que declaram fazer agricultura orgânica certificada, verifica-se que a macrorregião Sudeste passou a ocupar o lugar de liderança nesse indicador, com 19.666 unidades de produção orgânica certificada. Na sequência aparecem as macrorregiões Nordeste (16.710) e Sul (16.710). Por fim, Norte (7.935) e Centro-Oeste (6.826). Quando analisados os indicadores proporcionais da relação entre as unidades de produção orgânica e número total de unidades agropecuárias da macrorregião, verifica-se que as posições de destaque são ocupadas pelas macrorregiões Sudeste (2,03\%) e Centro-Oeste $(1,97 \%)$. Sul $(1,59 \%)$ e Norte $(1,37 \%)$ aparecem na sequência e por fim, a macrorregião Nordeste $(0,72 \%)$.

Por fim, os dados do Censo Agropecuário de 2006, pelo método empregado para coletar as informações referentes a agricultura orgânica, como já detalhado, possibilitam cruzar os índices de certificação e associação com cooperativas nas unidades agropecuárias que fazem agricultura orgânica. Na Tabela 3 apresenta-se os dados do Censo Agropecuário de 2006 relativos a agricultura orgânica, analisando os índices de certificação e associação com cooperativas.

Tabela 3 - Número de estabelecimentos agropecuários da agricultura orgânica, estratificados pela certificação, associados a cooperativas

\begin{tabular}{|c|c|c|c|c|c|c|c|c|c|c|}
\hline \multirow[t]{3}{*}{ Região } & \multirow{3}{*}{$\begin{array}{c}\begin{array}{c}\text { Agricultura } \\
\text { Orgânica }\end{array} \\
\text { Total } \\
\end{array}$} & \multicolumn{3}{|c|}{ Fazem } & \multicolumn{3}{|c|}{$\begin{array}{c}\text { Fazem e são } \\
\text { certificados por } \\
\text { entidade credenciada }\end{array}$} & \multicolumn{3}{|c|}{$\begin{array}{l}\text { Fazem e não são } \\
\text { certificados }\end{array}$} \\
\hline & & \multirow{2}{*}{$\begin{array}{c}\text { Total } \\
90.498 \\
\end{array}$} & \multicolumn{2}{|c|}{ Cooperativa } & \multirow{2}{*}{\begin{tabular}{|l|} 
Total \\
5.106 \\
\end{tabular}} & \multicolumn{2}{|c|}{ Cooperativa } & \multirow{2}{*}{$\begin{array}{l}\text { Total } \\
85 \cdot 392 \\
\end{array}$} & \multicolumn{2}{|c|}{ Cooperativa } \\
\hline & & & $5 \cdot 358$ & $5,92 \%$ & & 804 & $15,75 \%$ & & 4.554 & $5,33 \%$ \\
\hline \multirow[t]{2}{*}{ Brasil } & Não-familiar & 15.693 & 1.681 & $10,71 \%$ & 1.490 & 307 & $20,60 \%$ & 14.203 & 1374 & $9,67 \%$ \\
\hline & Familiar & 74.805 & 3.677 & $4,92 \%$ & 3.616 & 497 & $13,74 \%$ & 71.189 & 3180 & $4,47 \%$ \\
\hline \multirow{3}{*}{ Norte } & Total & 6.133 & 1.85 & $3,02 \%$ & 351 & 37 & $10,54 \%$ & $5 \cdot 782$ & 148 & $2,56 \%$ \\
\hline & Não-familiar & 925 & 57 & $6,16 \%$ & 73 & 18 & $24,66 \%$ & 852 & 39 & $4,58 \%$ \\
\hline & Familiar & 5.208 & 128 & $2,46 \%$ & 278 & 19 & $6,83 \%$ & 4.930 & 109 & $2,21 \%$ \\
\hline \multirow{3}{*}{ Nordeste } & Total & 42.236 & 873 & $2,07 \%$ & 1.218 & 112 & $9,20 \%$ & 41.018 & 761 & $1,86 \%$ \\
\hline & Não-familiar & $5 \cdot 778$ & 306 & $5,30 \%$ & 390 & 65 & $16,67 \%$ & $5 \cdot 388$ & 241 & $4,47 \%$ \\
\hline & Familiar & 36.458 & 567 & $1,56 \%$ & 828 & 47 & $5,68 \%$ & 35.630 & 520 & $1,46 \%$ \\
\hline \multirow{3}{*}{ Sudeste } & Total & 18.715 & 1.857 & $9,92 \%$ & 1.366 & 272 & $19,91 \%$ & $17 \cdot 349$ & 1.585 & 9,14\% \\
\hline & Não-familiar & 4.626 & 786 & $16,99 \%$ & 535 & 121 & $22,62 \%$ & 4.091 & 665 & $16,26 \%$ \\
\hline & Familiar & 14.089 & 1.071 & $7,60 \%$ & 831 & 151 & $18,17 \%$ & 13.258 & 920 & $6,94 \%$ \\
\hline \multirow{3}{*}{ Sul } & Total & 19.276 & 2.095 & $10,87 \%$ & 1.924 & 348 & $18,09 \%$ & $17 \cdot 352$ & 1.747 & $10,07 \%$ \\
\hline & Não-familiar & 3.178 & 413 & $13,00 \%$ & 376 & 88 & $23,40 \%$ & 2.802 & 325 & $11,60 \%$ \\
\hline & Familiar & 16.098 & 1.682 & $10,45 \%$ & 1.548 & 260 & $16,80 \%$ & 14.550 & 1.422 & $9,77 \%$ \\
\hline \multirow{3}{*}{$\begin{array}{l}\text { Centro- } \\
\text { Oeste }\end{array}$} & Total & 4.138 & 348 & $8,41 \%$ & 247 & 35 & $14,17 \%$ & 3.891 & 313 & $8,04 \%$ \\
\hline & Não-familiar & 1.186 & 119 & $10,03 \%$ & 116 & 15 & $12,93 \%$ & 1.070 & 104 & $9,72 \%$ \\
\hline & Familiar & 2.952 & 229 & $7,76 \%$ & 131 & 20 & $15,27 \%$ & 2.821 & 209 & $7,41 \%$ \\
\hline
\end{tabular}

Referente ao ano de 2006, dos 90.498 estabelecimentos que faziam agricultura orgânica, apenas 5.106 (5,64\%) eram certificados. Para Niederle e Almeida (2013) a certificação representa um dos grandes desafios da agricultura orgânica no país. Os achados de Mazzoleni e Nogueira (2006) corroboram essa ideia, ao revelarem que propriedades certificadas atingem índices de faturamento e lucratividade significativamente superior do que propriedades da agricultura orgânica em processo de conversão (não certificadas). Para os autores, a certificação orgânica é fator que agrega valor ao preço do produto vendido.

As macrorregiões Sul e Sudeste apresentaram em 2006 o maior número absoluto e proporcional de propriedades certificadas, se comparado com as demais macrorregiões. Resultado 
interessante revela que essas duas macrorregiões também são as que apresentam maior número absoluto e proporcional de propriedades associadas com cooperativas. Esse achado pode ser reforçado quando comparados com os dados das propriedades que fazem agricultura orgânica e possuem certificações. Em termos de Brasil, enquanto 15,75\% das propriedades certificadas estão associadas com cooperativas, nas propriedades não certificadas, esse índice atinge apenas 5,33\%. Essa tendência repete-se em todas as macrorregiões.

Dessa forma, pode-se aferir que os processos cooperativos são uma forma de organização que auxilia as unidades que fazem agricultura orgânica a obter a certificação da produção. Conforme Dias et al. (2016), a certificação representa para os estabelecimentos que fazem agricultura orgânica vantagens competitivas, que permite a sua utilização como diferencial de mercado, mecanismo de confiança, lealdade e uma forma de impedir produtores oportunistas de se passarem por produtores orgânicos. Assim sendo, esse indicador pode representar uma tendência de que as unidades de produção orgânica integradas com cooperativas são mais inclinadas a produzir mediante o uso de práticas orgânicas certificadas, que agregam valor ao que é produzido e elevam os rendimentos das propriedades agrícolas.

Assim é que, portanto, uma pergunta pode emergir da leitura dos dados: ações cooperativistas são agenciadoras do crescimento exponencial dos níveis de certificação dos estabelecimentos agropecuários que fazem agricultura orgânica no Brasil? Em reposta a essa interrogação, na seção que segue, busca-se discutir as contribuições de Chayanov para análise do cenário da cooperação na agricultura orgânica.

\section{Contribuições de Chayanov para a Cooperação na Agricultura Orgânica}

Os dados dos Censos Agropecuários de 2006 e 2017 mostram que os agricultores com produção orgânica são, em sua maioria, estabelecimento de agricultura familiar. Se ora os camponeses são vistos como atrasados, pobres e sem chances de sobreviver e ora são idealizados e apontados como a solução alimentar para o mundo (PLOEG, 2016), os dados demostram a importância da agricultura familiar para a produção orgânica no Brasil. Desse modo, a cooperação e as formas de organização da produção orgânica, estão também fortemente atravessadas pela lógica da agricultura familiar camponesa, que perpassa em diversos momentos as práticas que compõe o que faz sentido para as pessoas fazerem.

O agricultor familiar, que aparentemente mantem a sua autonomia econômica e independência, na medida em que busca acessos aos mercados, sem os quais ele não pode realizar a produção de seu trabalho e nem adquirir para si os meios de produção e as tecnologias necessários, complexifica a organização da agricultura para novas bases, transformando a unidade agrícola em um negócio. Nesse cenário de complexificação da agricultura, o cooperativismo representa uma possibilidade de organização que permite a unidade familiar se desenvolver e alcançar o bem-estar, por meio de processos de integração com cooperativas, que elevam à padrões superiores os níveis e a qualidade da produção agrícola.

Ao considerar os desafios da agricultura orgânica no Brasil, a organização cooperativa surge como meio importante para que o agricultor consiga migrar de um sistema convencional para modos de produção orgânica. A agricultura orgânica exige conhecimentos, etapas de processo produtivo de vários cultivos, bem como o manejo com os elementos naturais, diferentes daqueles empregados em um modo convencional de fazer agricultura. A agricultura orgânica não conta com a "facilidade e eficiência" da utilização de dessecante, pesticida, adubo sintético e muitos outros, o que exige diferentes saberes e técnicas sobre como fazer agriculta orgânica. Nesse processo de conversão, o cooperativismo, para além da função de comercialização dos produtos e acessos aos mercados, pode representar um importante meio para que esses saberes e técnicas sejam convertidos em capacitações, orientações, trocas de conhecimentos entre vizinhos e assistência técnica para os agricultores.

Além disso, historicamente, a produção de orgânicos se estruturou sobre ações coletivas de ONGs, movimentos sociais, sindicatos e outras organizações. Essas ações coletivas partem da ideia de trocas em que as partes se beneficiam e que através delas é possível compensar as carências 
econômicas e sociais, que marcaram a agricultura orgânica no Brasil. Essa característica pode ser explorada como facilitadora para que o produtor de orgânicos ingresse em sistemas cooperativos. As iniciativas coletivas, indubitavelmente podem se desenvolver mais e mais, ampliando e organizando formas superiores de produção cooperativas em novas esferas da agricultura de produção orgânica.

Os dados do Censo Agropecuário de 2006 destacam um importante indicador que reforça a importância da cooperação para a produção orgânica no Brasil, revelando que os agricultores associados com cooperativas possuem indicadores melhores acerca da certificação da produção orgânica, em comparação com os que não possuem essas relações com cooperativas. Como apontam alguns estudos empíricos, a certificação de alimentos encontra muitos limites e contradições nos mercados agroalimentares alternativos (DIAS et al., 2015), entretanto, permite a definição de um padrão de qualidade confiável, o comércio a distância, a diferenciação dos produtos (HATANAKA; BAIN; BUSCH, 2005) e garante melhores resultados aos produtores (MAZZOLENI; NOGUEIRA, 2006). Conforme os dados do Censo de 2006, parece correto afirmar que a associação com cooperativas facilita os processos de certificação dos produtores orgânicos. Assim, a cooperação pode representar uma forma de organização que promove acesso aos meios de produção e às tecnologias pelos agricultores que fazem agricultura orgânica. Por isso, que Chayanov interessa aqui.

O cooperativismo, na visão de Chayanov (2017), representa o melhor caminho, e talvez o único possível, para introduzir na economia camponesa elementos de uma economia de mercado. O cooperativismo pode representar uma forma de organização que permite o aumento da escala de produção e a inserção dos produtores orgânicos aos mercados, principalmente os da agricultura familiar, que enfrentam dificuldades econômicas e sociais para isso, visando atender a demanda por produtos orgânicos, crescente no Brasil e no mundo. Ao considerar os ótimos diferenciais das unidades de produção orgânica, pode-se analisar uma série de áreas nas quais a produção em grande escala dará imediatamente uma grande vantagem direta. Assim sendo, torna-se possível elencar as tarefas de grande porte e na relação com os vizinhos uni-las em uma grande tarefa geral, sem interromper os trabalhos das outras áreas da propriedade e não destruindo a unidade econômica de trabalho familiar.

Os dados comparativos dos Censos Agropecuários de 2006 e 2017 revelam uma tendência de fortalecimento das relações de associações entre os estabelecimentos agropecuários e as cooperativas. Ainda, esse fortalecimento se deu especialmente na categoria da agricultura familiar. Conforme Mazzoleni e Nogueira (2006) são os agricultores familiares mais pobres que representam a maioria significativa de estabelecimentos que fazem agricultura orgânica no país, o que, para os autores, pode ser consequência das dificuldades impostas pela falta da certificação para acessar e construir novos mercados.

Essas carências da agricultura familiar orgânica, podem ser superadas, explorando os diferencias dessa categoria e fortalecendo os processos cooperativos. Para Chayanov (2017) que sustenta a cooperação como uma facilitadora do acesso aos meios de produção e às tecnologias, esses dados podem representar um progresso da agricultura brasileira no desenvolvimento de um modelo econômico e social de organização eficaz na alocação individual dos resultados alcançados de forma coletiva. As ações cooperativas centradas na busca de padrões de qualidade, transmissão de saberes e práticas, aquisição de tecnologias compartilhadas, podem auxiliar os produtores nos processos de certificação de suas unidades, e consequentemente, aumentar a renda e o patrimônio das famílias.

A concepção de Chayanov (2017) defende um modelo de cooperação que considera extremamente útil cooperar, mesmo quando não produzir qualquer "lucro" líquido como empresa, mas, ainda assim, aumentar as rendas de seus membros. Assim, o resultado dos processos cooperativos é mensurado em termos de melhorias nas rendas e patrimônios daqueles que cooperam. O cooperativismo, ancorado nesse pressuposto possibilita que as propriedades da agricultura familiar orgânica, em geral detentoras de menos recursos e tecnologias, superem suas limitações de produção e comercialização, visando a melhoria da renda, o patrimônio e a qualidade vida das famílias.

As cooperativas agrícolas na visão de Chayanov (2017) trazem consigo a concentração e a organização da produção agrícola segundo padrões novos e mais elevados, ajudando os pequenos produtores a adaptarem o plano organizativo de sua unidade de acordo com a política de comercialização e processamento cooperativos. Na medida que a cooperativa alcança o sucesso, 
inevitavelmente, aproveitam-se do êxito para abarcarem ainda mais amplamente os setores produtivos da economia camponesa (criando associações de usuários de máquinas e implementos, espaços de reunião, associações voltadas para a inspeção e a linhagem do gado, o processamento conjunto, a melhoria do solo etc.). Parte dos gastos envolvidos nesse tipo de produção cooperativa são cobertos, e devem sê-lo, por questão de princípios, pelos lucros derivados da comercialização, das compras e dos créditos.

Assim, o conceito dos ótimos diferenciais de Chayanov ajuda a discutir as múltiplas formas de cooperação que podem se constituir na agricultura familiar orgânica, considerando o contexto social e econômico. Ao conceber o plano organizativo de uma unidade agrícola e, em seguida, o dividi-los em seus elementos constituintes para examinar quais desses elementos são mais adequados para organização cooperativa, pode-se determinar todos os tipos concebíveis de cooperação (CHAYANOV, 2017).

Dessa forma, a análise da cooperação no contexto da agricultura familiar de produção orgânica, permite um olhar para a pluriatividade das unidades rurais da agricultura familiar, a diversificação de mercados, a coexistência de formas de organizar dos modelos convencional e alternativo de agricultura e práticas de cooperação não institucionalizadas, espontâneas dentro de um mesmo espaço, e a diversidade de formas de cooperação - de produção, comercialização, serviços e etc. Aspectos que merecem investigação para melhor compreender como a cooperação acontecem nesses contextos.

\section{Considerações Finais}

Neste artigo buscou-se analisar de que modo o cooperativismo vem contribuindo com a rápida expansão da produção de orgânicos no Brasil. A partir dos dados dos Censos Agropecuários realizados em 2006 e 2017 foi possível mapear três indicadores importantes para pautar a discussão proposta: número de unidades agropecuárias associadas com cooperativas; número de unidades agropecuárias que fazem produção orgânica; número de unidades agropecuárias que fazem produção orgânica e são certificadas. Com base nesses indicadores foi possível tecer análises comparativas entre as categorias agricultura familiar e não-familiar, bem como uma análise histórica acerca das mudanças ocorridas no cenário entre os anos de 2006 e 2017.

Em síntese, do conjunto de dados apresentados acerca dos Censos Agropecuários, é preciso destacar três pontos. Primeiro, o crescimento exponencial entre os anos de 2006 e 2017 no número de unidades agropecuárias que fazem agricultura orgânica e são certificadas, em todas as macrorregiões do país, assim como nas categorias da agricultura familiar e não-familiar. Segundo, é relevante observar que a categoria sócio-política da agricultura familiar representa o grande quantitativo de estabelecimentos agropecuários que praticam agricultura orgânica no Brasil. Esses dados, corroboram tanto as pesquisas que mostram o crescimento na demanda por produtos orgânicos no Brasil e no mundo, quanto os autores que sustentam a potencialidade e a oportunidade para a agricultura familiar abarcar essa fatia do mercado. Por fim, lançando olhares sobre as unidades que fazem agricultura orgânica e possuem certificações verifica-se que enquanto 15,7\% das propriedades certificadas estão associadas com cooperativas, nas propriedades não certificadas, esse índice atinge apenas 5,3\%.

Os dados dos Censos podem ser tomados como importantes sinalizadores para análises mais profundas do contexto social no qual tais estabelecimentos que fazem produção orgânica no Brasil estão inseridos. Uma leitura desse cenário possibilita os contornos e relações estabelecidos entre a agricultura orgânica e a agricultura familiar. Para discutir essa relação, buscou-se aporte teórico nos escritos de Chayanov (2017). A cooperação pode ser uma forma de compensar as carências e as dificuldades das pequenas unidades agrícolas, como afirma Chayanov (2017)?

Embora a resposta possa parecer simples, um olhar sobre esse contexto, exige um entendimento das formas de organização da agricultura familiar orgânica, considerando o caráter heterogêneo, difuso, complexo e em constantes fluxos e transformações. Pautando-se nas teorizações de Chayanov é possível compreender como a organização social da agricultura familiar orgânica potencializa mais e mais tipos de cooperações. Algumas questões podem ser 
colocadas: De que agricultura estamos falando? Como ocorre a organização social da agricultura familiar orgânica? Como se constituem as relações com os mercados? Quais são os processos de cooperação que constituem esse campo? Como se constituem os diferenciais ótimos que garantem o sucesso do modelo de cooperação? Como a cooperação acontece neste contexto de forma a garantir a manutenção, reprodução e desenvolvimento da agricultura familiar orgânica?

Os dados dos Censos Agropecuários demostram que a agricultura orgânica brasileira ainda é pouco expansiva. Em face do reconhecimento potencial da agricultura familiar orgânica e seu papel para o desenvolvimento sustentável, e sobretudo, o crescimento da demanda por produtos orgânicos no Brasil e no mundo, acredita-se que os processos cooperativos são um modo de organização que desenvolve essa categoria. Ações do Estado e as políticas púbicas poderiam se beneficiar desta capacidade organizacional para tornar mais efetivas a superação das múltiplas carências socioeconômicas e produtivas dessa categoria. Conforme destaca Chayanov (2017, p. 88) pode-se "observar que muitos dos tipos de cooperação que identificamos analiticamente ainda não existem de fato. Ainda não foram descobertos na prática, assim como nossos químicos ainda não descobriram muitos dos elementos da tabela de elementos químicos de Mendeleyev". Questões que só poderão ser respondidas com estudos empíricos.

\section{Referências}

ABRAMOVAY, R. O admirável mundo novo de Alexander Chayanov. Estudos Avançados, v. 12, n. 32, p. 69-74, 1998.

ALMEIDA, J. A construção social de uma nova agricultura: tecnologia agrícola e movimentos sociais no sul do Brasil. 2. ed. Porto Alegre: Editora da UFRGS, 2009.

ALTIERI, M. Agroecologia: bases científicas para uma agricultura sustentável. Guaíba: Agropecuária, 2002.

BEZERRA, M.C.L.; VEIGA, J.E. (Coord.) Agricultura Sustentável. Brasília: Ministério do Meio Ambiente; Instituto Brasileiro do Meio Ambiente e dos Recursos Naturais Renováveis; Consórcio Museu Emílio Goeldi, 2000.

BRASIL. Instrução Normativa no 7 de 17 de maio de 1999. Estabelece as normas de produção, tipificação, processamento, envase, distribuição, identificação e de certificação da qualidade para os produtos orgânicos de origem vegetal e animal. Diário Oficial da União, Brasília, 1999.

BRASIL. Lei n. 10.831, de 23 de dezembro de 2003. Dispõe sobre Agricultura Orgânica e dá outras providências. Diário Oficial da União, Brasília, 2003.

BRASIL. Lei n. 11.326, de 24 de julho 2006. Estabelece as diretrizes para a formulação da Política Nacional da Agricultura Familiar e Empreendimentos Familiares Rurais. Diário Oficial da União, Brasília, 2006.

BREKKE, K. A.; KVERNDOKK, S.; NYBORG, K. An economic model of moral motivation. Journal of Public Economics, v. 87, n. 9-10, p. 1967-1983, 2003.

CHAYANOV, A. L'economia di lavoro, scriti scelti, a cura di Fiorenzo Sperottto. Milão: Franco Angeli/INSOR, 1988.

CHAYANOV, A. A teoria das cooperativas camponesas. Revisão e tradução de Regina Vargas. Porto Alegre: Editora da UFRGS, 2017. 
DALCIN, D.; SOUZA, A. R. L. de; FREITAS, J. B. de; PADULA, A. D.; DEWES, H. Organic products in Brazil: from an ideological orientation to a market choice. British Food Journal, v. 116, n. 12, p. 1998 - 2015, 2014.

DAWES, R. M. Social dilemmas. Annual Review of Psychology, v. 31, p. 169-193, 1980.

DAWES, R. M.; THALER, R. H. Anomalies: Cooperation. Journal of Economic Perspectives, v. 2, n. 3, p. 187-197, 1988.

DIAS, V. V.; SCHULTZ, G.; SCHUSTER, M. S.; TALAMINI, E.; RÉVILLION, J. P. O mercado de alimentos orgânicos: um panorama quantitativo e qualitativo das publicações internacionais. Ambiente \& Sociedade, n. 1, p. 161-182, 2015.

DIAS, V. V.; SALVATE, N. B.; RÉVILLION, J. P.; SCNEIDER, S. A importância da certificação nos circuitos curtos de alimentos orgânicos. Revista ESPACIOS, v. 37, n. 3, 2016.

FEHR, E.; SCHMIDT, K. M. A Theory of fairness, competition, and cooperation. The Quarterly Journal of Economics, v. 114, n. 3, p. 817-868, 1999.

GRISA, C.; SCHNEIDER, S. Três Gerações de Políticas Públicas para a Agricultura Familiar e Formas de Interação entre Sociedade e Estado no Brasil. Revista Economia e Sociologia Rural, v. 52, Supl. 1, p. S125-S146, 2014.

HARDIN, G. The tragedy of the commons. Science, v. 162, n. 3859, p. 1243-1248, 1968.

IBGE. Censo agropecuário 2006. Brasil, Grandes Regiões e Unidades da Federação. Primeiros Resultados. Disponível em: http://biblioteca.ibge.gov.br/visualizacao/periodicos/51/agro_20o6.pdf. Acesso em: 30 ago. 2018.

IBGE. Censo agropecuário 2017. Brasil, Grandes Regiões e Unidades da Federação. Primeiros Resultados. Disponível em: https://sidra.ibge.gov.br/. Acesso em: 20 nov. 2019.

IFOAM. Growth continues: 43.7 million hectares of organic agricultural land orldwide. Disponível em: < http://www.ifoam.bio/sites/default/files/press-releaseworld-2016-english.pdf >. Acesso em: 18 ago. 2018.

HATANAKA, M.; BAIN, C.; BUSCH, L. Third-party certification in the global agrifood system. Food Policy, v. 30, p. 354-369, 2005.

LOURENÇO, A. V.; SCHNEIDER, P.; GAZOLLA, M. A agricultura orgânica no brasil: um perfil a partir do Censo Agropecuário 2006. Revista Extensão Rural, v.24, n.1, p. 42-61, 2017.

MAZZOLENI E. M.; NOGUEIRA J. M. Agricultura orgânica: características básicas do seu produtor. Revista de Economia e Sociologia Rural, v .44, n. 2, p. 263-293, 2006.

MUTERSBAUGHT, T. et al. (2005) Editorial. Certifying rural spaces: quality-certified products and rural governance. Journal of Rural Studies, v. 21, n. 4, p. 381-388, 2005.

NIEDERLE, P. A.; ALMEIDA, L. A nova arquitetura dos mercados para produtos orgânicos: o debate da convencionalização. In: NIEDERLE, P. A.; ALMEIDA, L.; VEZZANI, F. M. (Orgs.). Agroecologia: práticas, mercados e políticas para uma nova agricultura. Curitiba: Kairós. 2013, p. 23-68. 
NIEDERLE, P. A.; VERARDI, M. A.; CONTERATO, M. A. A pesquisa sobre Agricultura Familiar no Brasil - aprendizagens, esquecimentos e novidades. Revista Economia e Sociologia Rural, v. 52, Supl. 1, p. Soog-So24, 2014.

NYBORG, K.; HOWARTH, R. B.; BREKKE, K. A. Green consumers and public policy: On socially contingent moral motivation. Resource and Energy Economics, v. 28, n. 4, p. 351-366, 2006.

OLSON, M. The logic of collective action: Public goods and the theory of groups. Cambridge: Harvard University Press, 1965.

OSTROM, E. Governing the commons: The evolution of institutions for collective action. Cambridge: Cambridge University Press, 1990.

PLOEG. J. D. V. D. Camponeses e a arte da agricultura. Tradução de Claudia Freire. Porto Alegre: Editora UFRGS, 2016.

RAGANOLD, J. P.; WACHTER, J. M. Organic agriculture in the twenty-first century. Nature Plants, V. 2, Article number 15221, 2016.

RENARD, M. C. Quality certification, regulation and power in fair trade. Journal of Rural Studies, v. 21, n. 4, p. 419-431, 2005.

ROEMER, J. E. Kantian equilibrium. Scandinavian Journal of Economics, v. 112, n. 1, p. 1- 24, 2010.

ROEMER, J. E. Kantian optimization: A microfoundation for cooperation. Journal of Public Economics, v. 127, p. 45-57, 2015.

STRATE, M. F. Cooperativismo como alternativa de fortalecimento da agricultura familiar: a obra de Chayanov. Revista do Programa de Pós-Graduação em Extensão Rural (UFV), v. 7. n. 1, 2018.

VERONEZZI, F.; BASTOS, T. L. Agricultura familiar orgânica: alternativa de permanência no campo para o pequeno produtor da região centro- sul do estado do Paraná. Encontro Nacional de Geografia Agrária, XXI, Uberlândia, 2012. Anais..., Uberlândia, 2012. 